\title{
Broccoli Cultivar Performance under Organic and Conventional Management Systems and Implications for Crop Improvement
}

\author{
Erica N. C. Renaud,^ Edith T. Lammerts van Bueren, Maria João Paulo, \\ Fred A. van Eeuwijk, John A. Juvik, Mark G. Hutton, and James R. Myers
}

\begin{abstract}
To determine if present commercial broccoli cultivars meet the diverse needs of organic management systems, such as adaptation to low $\mathrm{N}$ input, mechanical weed management, and no chemical pesticide use, and to propose the selection environments for crop improvement for organic production, we compared horticultural trait performance of 23 broccoli cultivars $(G)$ under two management $(M)$ systems (organic and conventional) in two regions of the United States (Oregon and Maine), including spring and fall trials. In our trials, location and season had the largest effect on broccoli head weight, with Oregon outperforming Maine, and fall trials outperforming spring plantings. $M$ main effects and $G \times M$ interactions were often small, but $G \times M \times E$ (location and season) were large. Cultivars with both greater head weight and stability under conventional conditions generally had high head weight and stability under organic growing conditions, although there were exceptions in cultivar rank between management systems. Larger genotypic variances and somewhat increased error variances observed in organic compared with conventional management systems led to repeatability for head weight and other horticultural traits that were similar or even higher in organic compared with conventional conditions. The ratio of correlated response (predicting performance under organic conditions when evaluated in conventional conditions) to direct response (predicted performance in organic when evaluated under organic conditions) for all traits was close to but less than 1.0 with the exception of bead uniformity. This would imply that in most cases, direct selection in an organic environment could result in a more rapid genetic gain than indirect selection in a conventional environment.
\end{abstract}

E.N.C. Renaud and E.T. Lammerts van Bueren, Wageningen UR Plant Breeding, Plant Sciences Group, Wageningen Univ., P.O. Box 386, 6700 AJ Wageningen, the Netherlands; M.J. Paulo, F.A. van Eeuwijk, Biometris, Plant Sciences Group, Wageningen University, P.O. Box 100, 6700 AC Wageningen, the Netherlands; J.A. Juvik, Dep. of Crop Sciences, Univ. of Illinois, 1201 W. Gregory Dr., 307 ERML, Urbana, IL 61801; M.G. Hutton, Highmoor Farm, University of Maine Cooperative Extension, P.O. Box 179, Monmouth, ME 04259; J.R. Myers, Dep. of Horticulture, Oregon State Univ., 4017 ALS Bldg., Corvallis, OR 97331. Received 9 Sept. 2013. *Corresponding author (erica.renaud@vitalisorganic.com).

Abbreviations: GDD, growing degree day; ME, Monmouth, Maine location; OP, open-pollinated cultivar; OR, Corvallis, Oregon location; POM, particulate organic matter.

ONTINUED GROWTH IN DEMAND in the organic sector has
spurred an increase in organic crop production area in the
United States, with more than two million hectares in 2011 (Willer
and Kilcher, 2012). The seed industry is challenged to satisfy the
demands of organic agriculture, and often does not understand
the special requirements of an unfamiliar agricultural system that
is characterized by a greater diversity of requirements and criteria
compared with conventional management (Mäder et al., 2002).
Organic farms often differ substantially from nonorganic counter-
parts in the complexity of their crop rotations, number of crops,
production area, and market outlets. Organic farmers refrain from
using synthetically derived chemical inputs and rely largely on bio-
logical self-regulatory processes to maintain yield, leaving fewer
tools to manage crop production environments (Messmer et al.,
2012; Wolfe et al., 2008). Thus, organic farmers need cultivars that

Published in Crop Sci. 54:1539-1554 (2014).

doi: 10.2135/cropsci2013.09.0596

Freely available online through the author-supported open-access option.

(C) Crop Science Society of America | 5585 Guilford Rd., Madison, WI 53711 USA

All rights reserved. No part of this periodical may be reproduced or transmitted in any form or by any means, electronic or mechanical, including photocopying, recording, or any information storage and retrieval system, without permission in writing from the publisher. Permission for printing and for reprinting the material contained herein has been obtained by the publisher. 
are stable across a range of conditions, rather than varieties that are high yielding under optimal conditions, but prone to lose that yield advantage due to disease susceptibility or an inability to utilize available nutrients efficiently (Lammerts van Bueren et al., 2002).

Broccoli (Brassica oleracea var. italica Plenck), a significant crop in organic agriculture due to its market demand as well as its nutritional contribution to the U.S. diet (Verkerk et al., 2009), was grown on 743,088 production acres $(300,717$ ha) and generated U.S. \$47,629,515 in sales in 2011 (USDA NASS, 2012). The main conventional fresh market broccoli production areas in the United States are California and Arizona. Broccoli cultivars in the United States have been bred primarily for the agroclimatic requirements of these regions. Secondary commercial broccoli producing areas are Maine and Oregon, which are characteristically cool continental and cool Mediterranean type climates, respectively, and differ significantly from those of California and Arizona. Organic production in the United States is comprised of small acreages scattered across the country in a broad range of environments to service local and diverse food markets (USDA ERS, 2008; USDA NASS, 2012). These producers are dependent on the commercial cultivar assortment available that were developed predominantly for California and Arizona. The production environments for Oregon and Maine may be more representative of the growing conditions faced by organic growers located at higher latitudes on the east and west coasts.

Broccoli producers in the United States need cultivars that exhibit heat tolerance, head stability, and uniform maturation in the field, while others are seeking extended harvest from side-shoot development (Heather et al., 1992; Farnham and Bjorkman, 2011a, 2011b; Myers et al., 2012). Some desired traits in organic management are shared with conventional producers, such as drought tolerance, insect and disease resistance, and high yield. Other cultivar characteristics that are more important to organic producers include vigorous early growth, waxy leaves, ability to perform in soils with potentially low or fluctuating nutrient mineralization rates, and the ability to compete with weeds (Lammerts van Bueren et al., 2002, 2012; Lammerts van Bueren and Myers, 2012). This is particularly important in broccoli due to its relatively high $\mathrm{N}$ requirement and shallow fine root system, which limits its ability to take up water and nutrients (Pasakdee et al., 2006; Myers et al., 2012). Most studies investigating traits needed for organic farming systems have focused on field crops such as cereals (e.g., Murphy et al., 2007; Löschenberger et al., 2008; Przystalski et al., 2008; Wolfe et al., 2008; Annicchiarico et al., 2010; Reid et al., 2009, 2011; Kirk et al., 2012; Koutis et al., 2012), with few conducted on vegetable crops (Osman et al., 2008; Lammerts van Bueren et al., 2012; Myers et al., 2012). None of these studies have evaluated commercial cultivars of broccoli across multiple regions or seasons for agronomic performance under organic conditions.

Some studies comparing performance of genotypes in organic and conventional management systems have shown that for certain traits, cultivar rank varies between the two management systems (e.g., for winter wheat, Triticum aestivum L.: Murphy et al., 2007; Baresel et al., 2008; Kirk et al., 2012; for lentil, Lens culinaris Medik.: Vlachostergios and Roupakias, 2008; for maize, Zea mays L.: Goldstein et al., 2012), while others have shown no differences in ranking performance (for maize: Lorenzana and Bernardo, 2008; for cereals: Przystalski et al., 2008; for onion, Allium cepa L.: Lammerts van Bueren et al., 2012). The results of these studies have profound implications for organic variety selection and breeding strategies, and raise questions as to the need for cultivars to be bred with broad adaptability or specific adaptation for the requirements of regional organic management. Two different outcomes have been identified. First, some studies showed cultivar performance varies between management systems with significant differences in ranking, and in some cases, low genetic correlations for lower heritability traits (e.g., Kirk et al., 2012; Murphy et al., 2007), resulting in the recommendation that cultivars intended for organic agriculture should be selected only under organic conditions. Second, other studies indicated that rankings in cultivar performance between management systems were similar with high genetic correlations, suggesting that breeding can be conducted under conventional conditions, with the caveat that advanced breeding lines can be tested under organic conditions for less heritable traits (e.g., Löschenberger et al., 2008; Lorenzana and Bernardo, 2008).

The vegetable seed industry has not developed broccoli cultivars selected for performance in organic management systems. As a result, a collective of public breeders and organic growers have attempted to develop bioregionally bred broccoli cultivars for organic systems (see Northern Organic Vegetable Improvement Collaborative, http:// eorganic.info/NOVIC, verified 4 Apr. 2014). In the interim, this leaves no choice but for organic growers to use cultivars bred under conventional conditions for many crops (Lammerts van Bueren and Myers, 2012). While seeds of some cultivars are produced under organic conditions, the majority of organic producers are using conventionally produced and postharvest untreated seeds (Dillon and Hubbard, 2011). With the private sector becoming more interested in breeding for the organic market, many questions arise as to what are the highest priority traits, what is their heritability under variable, sometimes lowinput organic growing conditions, and what is the most appropriate selection environment. To better understand how and whether broccoli cultivars perform differently under organic conditions and to determine whether selection under organic growing conditions is necessary 
to service the needs of growers in diverse regions, a large genotype $\times$ environment $\times$ management $(\mathrm{G} \times \mathrm{E}$ $\times$ M) study with 16 field trials was established in Oregon and Maine to evaluate a diverse set of cultivars, trialed under organic and conventional management. The study aimed to address the following questions: (i) do currently available broccoli cultivars perform differently for head weight and other horticulture traits in organic compared with conventional management systems in different regions and different seasons; (ii) is the relative ranking of cultivars the same under organic and conventional conditions; (iii) does heritability differ for certain traits under organic conditions compared with conventional conditions; and (iv) under which growing conditions and in what locations would selection for broccoli cultivars for organic agriculture be most effective?

\section{MATERIALS AND METHODS Plant Materials}

Twenty-three broccoli cultivars, including open pollinated $(\mathrm{OP})$ cultivars, inbred lines, and $\mathrm{F}_{1}$ hybrids, were included in the field trials (Table 1). These cultivars were selected to encompass varietal diversity in the targeted trial regions by organic and conventional growers, as well as to represent diverse genotypes and phenotypes that differed in their year of commercial introduction and the commercial seed company of origin.

\section{Field Trial Locations}

The cultivars were grown in paired organic and conventional fields at two U.S. locations [Maine (ME)-Monmouth $\left(44^{\circ} 14^{\prime} 19^{\prime \prime} \mathrm{N}, 7^{\circ} 2^{\prime} 8^{\prime \prime} \mathrm{W}, 61\right.$ masl); Oregon (OR)-Corvallis $\left(44^{\circ} 33^{\prime} 53^{\prime \prime} \mathrm{N}, 123^{\circ} 15^{\prime} 39^{\prime \prime} \mathrm{W} ; 76\right.$ masl)] in fall and spring during the 2006-2007 and 2007-2008 growing seasons. The paired organic and conventional fields within each location had similar soil types (ME: Woodbridge [coarse-loamy, mixed, active, mesic Aquic Dystrudepts]; OR organic: Malabon [fine, mixed, superactive, mesic Pachic Ultic Argixerolls], OR conventional: Chehalis [fine-silty, mixed, superactive, mesic Cumulic Ultic Haploxerolls]) and comparable climatic conditions (one growing degree day [GDD] or less between sites and negligible precipitation differences). In ME, both the conventional and organic trials were at University of Maine Cooperative Extension, Highmoor Farms Research Station, and adjacent to one another. The OR conventional field trials were located at the Oregon State University Vegetable Research Station and at a local organically managed commercial farm within $5 \mathrm{~km}$ and with a comparable elevation ( $<50$ foot) for the organic field trials. Both organic trial sites had been managed organically for over $5 \mathrm{yr}$ and were mature organically managed production systems at the onset of the study.

\section{Field Design}

Field trials consisted of the 23 broccoli cultivars arranged in a randomized complete block design with three replicates under both organic and conventional management at $\mathrm{MN}$ and $\mathrm{OR}$ locations during 2007-2008 growing season. An individual treatment plot contained 36 plants that were planted in three
Table 1. Overview of broccoli cultivars, showing origin and main characteristics, included in paired organic- conventional field trials 2006 to 2008 .

\begin{tabular}{|c|c|c|c|c|c|}
\hline Cultivar & $\begin{array}{l}\text { Abbre- } \\
\text { viation }\end{array}$ & Origin & $\begin{array}{c}\text { Cultivar } \\
\text { type }^{\dagger}\end{array}$ & $\begin{array}{c}\text { Date of } \\
\text { market } \\
\text { entry }\end{array}$ & $\begin{array}{c}\text { Maturity } \\
\text { classifi- } \\
\text { cation }\end{array}$ \\
\hline Arcadia & ARC & Sakata & $F_{1}$ & 1985 & $L$ \\
\hline B1 10 & B11 & Rogers & $F_{1}$ & 1988 & $M$ \\
\hline Batavia & BAT & Bejo & $F_{1}$ & 2001 & M \\
\hline Beaumont & BEA & Bejo & $F_{1}$ & 2003 & L \\
\hline Belstar & BEL & Bejo & $F_{1}$ & 1997 & L \\
\hline Diplomat & DIP & Sakata & $F_{1}$ & 2004 & L \\
\hline Early Green & EGR & $\begin{array}{l}\text { Seeds of } \\
\text { Change }\end{array}$ & OP & 1985 & $E$ \\
\hline Everest & EVE & Rogers & $F_{1}$ & 1988 & $E$ \\
\hline Fiesta & FIE & Bejo & $F_{1}$ & 1992 & L \\
\hline Green Goliath & GRG & Burpee & $F_{1}$ & 1981 & $M$ \\
\hline Green Magic & GRM & Sakata & $F_{1}$ & 2003 & M \\
\hline Gypsy & GYP & Sakata & $F_{1}$ & 2004 & $M$ \\
\hline Imperial & IMP & Sakata & $F_{1}$ & 2005 & L \\
\hline Marathon & MAR & Sakata & $F_{1}$ & 1985 & L \\
\hline Maximo & MAX & Sakata & $F_{1}$ & 2004 & L \\
\hline Nutribud & NUT & $\begin{array}{l}\text { Seeds of } \\
\text { Change }\end{array}$ & OP & 1990 & E \\
\hline OSU OP & OSU & $\begin{array}{c}\text { Jim Myers, } \\
\text { OSU }\end{array}$ & OP & 2005 & E \\
\hline Packman & PAC & Petoseed & $F_{1}$ & 1983 & $E$ \\
\hline Patriot & PAT & Sakata & $F_{1}$ & 1991 & $M$ \\
\hline Patron & PAN & Sakata & $F_{1}$ & 2000 & M \\
\hline Premium Crop & PRC & Takii & $F_{1}$ & 1975 & E \\
\hline USVL 048 & U48 & $\begin{array}{l}\text { Mark } \\
\text { Farnham, } \\
\text { USVL }\end{array}$ & inbred & $\begin{array}{c}\text { not } \\
\text { released }\end{array}$ & L \\
\hline USVL 093 & U93 & $\begin{array}{c}\text { Mark } \\
\text { Farnham, } \\
\text { USVL }\end{array}$ & inbred & $\begin{array}{l}\text { not } \\
\text { released }\end{array}$ & $M$ \\
\hline
\end{tabular}

† Cultivar types: F1 = hybrid, OP = open pollinated, inbred.

${ }^{\ddagger}$ Maturity classification: $E=$ early, $M=$ mid, $L=$ late.

rows of 12 plants at $46-\mathrm{cm}$ equidistant spacing within and between rows. In 2006, only 18 of the 23 cultivar entries were established in the OR and ME field trials, and there were only two replicates in the OR organic 2006 field trial. Field trials were conducted during three consecutive years (2006 to 2008) over two growing seasons that included two fall $(2006,2007)$ and two spring trials $(2007,2008)$.

\section{Field Management}

The primary management differences between the organic and conventional field trial sites are outlined in Table 2, which describes the management system and regionally appropriate fertility application tools, and the applied supplemental irrigation for the area of study. Cropping history and rotation are outlined per location. Mechanical and hand weed management were practiced for all sites. Baseline soil sampling for basic soil characteristics was performed as subsampling within plots, per trial site location before the start of each seasonal trial at the time of trial planting. Soils were analyzed for $\mathrm{pH}$, labile (available) $\mathrm{N}\left(\mathrm{mg} \mathrm{kg}^{-1}\right)$, and particulate organic matter (POM), a measure of longer-term available $\mathrm{N}$ taken prefertilization (N/ 
$\mathrm{kg}$ soil). There were no pest control applications in organic fields. In the conventional trials, diazinon was used for control of radish maggot and carbaryl (Sevin) was used for flea beetle control.

\section{Weather}

Weather data was collected from the two regional meteorological stations relative to the field experiments in Maine and Oregon to include maximum and minimum temperatures and precipitation per day for each trial duration. Across each trial period, GDDs were calculated by taking the average of the daily maximum and minimum temperatures minus the base temperature for broccoli (4.4 ${ }^{\circ} \mathrm{C}$; Maynard and Hochmuth, 2007).

\section{Field Data Collection}

As plots approached maturity, they were evaluated three times a week for broccoli heads that had reached commercial market maturity (approximately 10 to $12 \mathrm{~cm}$ in diameter for most of the cultivars, while retaining firmness as an indicator of maturity) and were evaluated for quality traits. Field quality evaluations were measured on a 1 to 9 ordinal scale. Traits included head shape $(1=$ flat shape; $9=$ high dome shape $)$, head surface $(1=$ very uneven; $9=$ smooth head), head color $(1=$ pale green; $9=$ dark green $)$, bead size $(1=$ large beads; $9=$ small beads), bead uniformity ( 1 = not uniform; 9 $=$ excellent uniformity), plant height (mean measurement of height of plant from base of stalk to tips of leaves in centimeters), and an overall plot quality rating $(1=$ poor overall performance; 9 = excellent overall performance) based on overall appearance, head quality, and uniformity of the entire plot. Five broccoli heads were trimmed to a uniform length of $18 \mathrm{~cm}$ from the crown to stalk at maturity. For each of the five heads, head weight (grams) and head diameter (centimeters) was measured. To determine average head weight, the mean was taken of the sum of the five individual head weight measurements. Head diameter was measured and averaged for five randomly harvested heads from each plot. Hollow stem was evaluated on a 1-to-9 scale $(1=$ many hollow stems to $9=$ no hollow stems). Maturity was measured based on days to harvest from the date seedlings were transplanted.

\section{Statistical Analysis}

Various linear mixed models were used for the analysis of trait variation. Our approach 
was comparable to that of Lorenzana and Bernardo (2008). All linear mixed models were fitted in GenStat 15 (VSN, 2012). The models can be formulated informally as:

$$
\begin{aligned}
\text { Response }= & \text { environment }+ \text { replicate within } \\
& \text { environment }+ \text { genotype }+ \text { genotype by } \\
& \text { environment interaction }+ \text { error }
\end{aligned}
$$

More formally, we can write the general form of our mixed models as

$$
y=\mathrm{E}+\mathrm{R}(\mathrm{E})+\mathrm{G}+\mathrm{G} \times \mathrm{E}+\mathrm{e}
$$

with the individual terms in the formal model corresponding to those in the informal model just above it.

Depending on the analysis, the terms included in $\mathrm{E}$ (the environments) varied. For the most general analysis, E contained all main effects and interactions of Season (S), Location (L), and Management $(\mathrm{M})$. Thus, in that case, $\mathrm{E}=\mathrm{S}+\mathrm{L}+\mathrm{S} \times \mathrm{L}+\mathrm{M}+$ $\mathrm{S} \times \mathrm{M}+\mathrm{L} \times \mathrm{M}+\mathrm{S} \times \mathrm{L} \times \mathrm{M}$ and $\mathrm{G} \times \mathrm{E}=\mathrm{G} \times \mathrm{S}+\mathrm{G} \times \mathrm{L}+\mathrm{G}$ $\times \mathrm{S} \times \mathrm{L}+\mathrm{G} \times \mathrm{M}+\mathrm{G} \times \mathrm{S} \times \mathrm{M}+\mathrm{G} \times \mathrm{L} \times \mathrm{M}+\mathrm{G} \times \mathrm{S} \times \mathrm{L} \times \mathrm{M}$, where the combination of $\mathrm{S}, \mathrm{L}$, and $\mathrm{M}$ defined individual trials. The term S (Season) contained a combination of year (2006, 2007, 2008) and season within year (spring, fall). Effectively, there were only four year by season within year combinations included: fall 2006, spring 2007, fall 2007, spring 2008). For convenience, in our general model, we fitted one factor (S) to cover the four trialing periods. However, other model formulations are possible. For example, we can define a factor Year (Y) with two levels (Level $1=$ Fall 2006 + Spring 2007; Level $2=$ Fall 2007 + Spring 2008) and factor S with two levels (spring, fall). The main effects of these factors $Y$ and $S$ plus their interaction covers the same variation as the original factor $S$ with four levels. We used this second formulation in analysis per location to obtain a more fine-grained interpretation of the variation.

All terms were assumed to be normally distributed with a proper variance. For ease of interpretation and to allow straightforward comparisons between traits, the variance components were reported as coefficients of variation, which is standard deviations as a percentage of the trait mean, that is,

$$
\mathrm{CV}=\frac{100 \sqrt{\mathrm{V}}}{\bar{x}}
$$

with $\mathrm{V}$ the variance for a particular model term, and $\bar{x}$ the trait mean. Repeatability (analogous to broad-sense heritability, but for unrelated genotypes) was calculated from the variance components as:

$$
\begin{aligned}
& \mathrm{H}=\mathrm{V}_{\mathrm{G}} /\left(\mathrm{V}_{\mathrm{G}}+\mathrm{V}_{\mathrm{GL}} / \mathrm{nL}+\mathrm{V}_{\mathrm{GS}} / \mathrm{nS}+\mathrm{V}_{\mathrm{GM}} / \mathrm{nM}\right. \\
&+\mathrm{V}_{\mathrm{GLS}} /(\mathrm{nL} \times \mathrm{nS})+\mathrm{V}_{\mathrm{GLM}} /(\mathrm{nL} \times \mathrm{nM})+\mathrm{V}_{\mathrm{GSM}} / \\
&(\mathrm{nS} \times \mathrm{nM})+\mathrm{V}_{\mathrm{GLSM}} /[\mathrm{nL} \times \mathrm{nS} \times \mathrm{nM})+\mathrm{V}_{\mathrm{e}} /(\mathrm{nL} \\
&\times \mathrm{nS} \times \mathrm{nM} \times \mathrm{nR})],
\end{aligned}
$$

where the variance components correspond to the terms in the mixed model above. The terms $\mathrm{nL}, \mathrm{nS}, \mathrm{nM}$, and $\mathrm{nR}$ represent the number of locations (2, Maine and Oregon), seasons (4, Fall 2006, Spring 2007, Fall 2007, Spring 2008), management (2, organic and conventional), and replicates (2 or 3 ), respectively.

The above model and repeatability was simplified when performing analyses per location, or per management regime.
For the first situation, analysis for Oregon and Maine separately, we omitted all terms that contain L. For the second situation, analysis for organic and conventional management separately, we omitted all terms containing $\mathrm{M}$.

To calculate genotypic means across all conditions, the general model defined above was used, but the genotypic main effect was assumed to be fixed instead of random. Similarly, genotypic means per location and management system were obtained by assuming fixed genotypic main effects as well as the relevant environmental effects $(\mathrm{L}, \mathrm{M})$ and their interactions $(\mathrm{G}$ $\times \mathrm{L}, \mathrm{G} \times \mathrm{M}$ ). These means were used to calculate correlations and for box plots and biplots (procedure dbiplot in GenStat). Pairwise comparisons between means were performed using GenStat procedure VMCOMPARISON. Correlations on the basis of genotypic means were referred to as genetic correlations.

To study correlations between conventional and organic conditions at the fine grained level of location by trialing period combinations, we used Spearman's rank correlations, because we were especially interested in rank changes.

A further comparison of conventional and organic conditions was performed by evaluating stability of performance versus mean performance for the set of varieties. Genotypic (in)stabilities under organic and conventional conditions were calculated as the variance for individual genotypes across all trials in the system.

Correlated Response theory (Falconer and Mackay, 1996) was used to assess the feasibility of selection for organic conditions (the target environment) under conventional conditions (the selection environment). The ratio of correlated response (for organic conditions using conventional conditions), CR, to direct response (for organic conditions in organic conditions), DR, can be used to decide whether it is possible to use selection under conventional conditions for improvement in organic systems; it was calculated as the product of the genetic correlation between organic and conventional systems $\left(r_{\mathrm{G}}\right)$ and the ratio of the roots of conventional and organic repeatabilities $\left(\mathrm{H}_{\mathrm{C}}\right.$ and $\mathrm{H}_{\mathrm{O}}$, respectively):

$$
\frac{\mathrm{CR}}{\mathrm{DR}}=r_{\mathrm{G}} \times \frac{\mathrm{H}_{\mathrm{C}}}{\mathrm{H}_{\mathrm{O}}} .
$$

Ratios smaller than 1 indicate that it is better to select under organic conditions when the aim is to improve the performance in organic conditions.

\section{RESULTS \\ Partitioning of Variance Components}

We fitted variance components models for all traits, where we report these variance components as coefficients of variation (CVs). We do not report the significance of the variance components, as almost all components were found to be significant by likelihood ratio tests, even for components that were close to zero. The information on the variation is best considered through the magnitude of the variance components and not through significance tests.

For head weight across all trials in both locations (L, Oregon versus Maine), we found that the environmental level S (four trialing periods) described the largest portion of the total variance (34\%), followed by $\mathrm{L}$ with a CV of 
18\% (Table 3). Management system (organic versus conventional) main effect was small $(<2 \%)$, but the three-way interaction $(\mathrm{L} \times \mathrm{S} \times \mathrm{M})$ had a $\mathrm{CV}$ of about $11 \%$. Genotype main effect was $13 \%$, and $\mathrm{G}$ interactions with $\mathrm{L}$ and $\mathrm{S}(14$ and $9 \%$, respectively), were larger sources of variation for head weight than $\mathrm{G} \times \mathrm{M}$ at $4 \%$. The $\mathrm{CV}$ for the four-way interaction $\mathrm{G} \times \mathrm{L} \times \mathrm{S} \times \mathrm{M}$ was $11 \%$. This large interaction was due to trial specific effects, because attempts to reduce the complexity of this interaction by ignoring years (so focusing on spring versus fall) or ignoring season within year (so focusing on year itself) failed (results not shown).

For days to maturity, the $\mathrm{L} \times \mathrm{S}$ interaction accounted for the largest source of variation (23\%), followed by $\mathrm{L}$ and $\mathrm{G}$ main effects of 10 and $7 \%$, and the three-way interaction $\mathrm{G} \times \mathrm{L} \times \mathrm{S}(8 \%)$. The $\mathrm{M}$ main effect and its interaction with $G$ was absent (0\%), and other two- and three-way interactions were small. The largest source of variation for bead size was $G$, as well as three- and four-way interactions $(G \times L \times S$ and $G \times L \times S \times M)$. There was no $\mathrm{L}$ main effect for this trait. For the overall quality rating, sources of variation were distributed among $G$ and $L$ main effects and G, L, and S interactions. For eight of 11 traits analyzed, the contribution of variation described by fourway interactions compared with other interaction terms in the model was relatively large. For this reason, we performed a partitioning of variance component analysis at each location and season within location to analyze the contribution of management system to variation at these trial levels (data not shown).

We performed variance components analyses for the separate locations Maine and Oregon to more closely examine the partitioning of the variation conditional on location. At the trial location level (Maine and Oregon), the partitioning of variance for head weight showed the same pattern as across all trials; trialing period was important, as $S$ contributed to the largest source of variation, followed by $\mathrm{Y} \times \mathrm{S}$ interactions (data not shown). For other traits such as bead size, again trialing period effects as $\mathrm{S}$ and $\mathrm{Y}$ effects were most important. For maturity, the $\mathrm{Y}$ effect in Maine accounted for the largest source of variation, but not in Oregon. With the higher means for head weight in Oregon (347 g) compared with Maine (261 g), the genotypic effect for most traits was larger in Oregon compared with Maine. As with the overall analysis, the $\mathrm{M}$ main effect was zero or small. Among $M$ interactions, the largest source of variation was associated with $\mathrm{G} \times \mathrm{Y} \times \mathrm{S} \times \mathrm{M}$ in both Maine and Oregon, with variances generally larger in Oregon (data not shown). When trials were analyzed by $\mathrm{S}$ and $\mathrm{L}$ separately, $\mathrm{M}$ main effect was also not significant for head weight and most traits; only in Maine Fall did the $\mathrm{M}$ have a large effect on plant height (data not shown). When trials were analyzed at the paired trial level per L, S, and Y level, we found that the $\mathrm{G} \times \mathrm{M}$ interaction was often significant (53 of 72 interactions [74\%] for nine traits $\times$ eight environments).

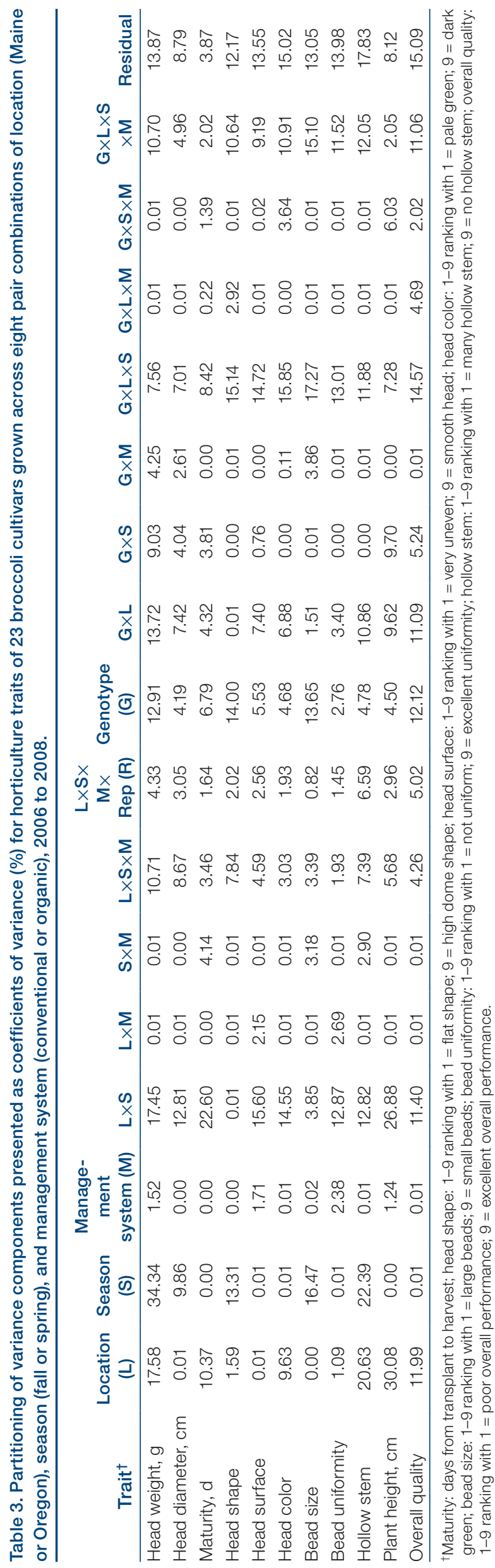



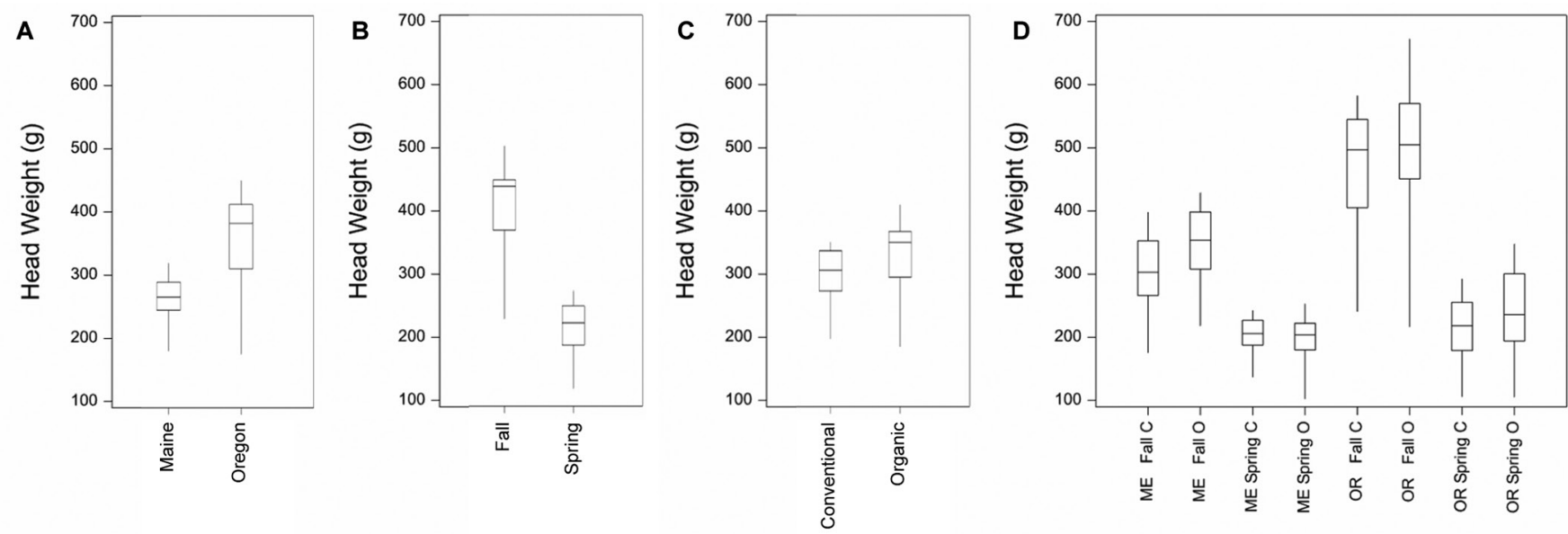

Figure 1. Comparison of broccoli cultivars for average head weight (g) grown (A) across all trials in two trial locations (Maine and Oregon, 2006 to 2008); (B) between seasons (fall or spring) across trials (2006 to 2008); (C) between two management systems (organic versus conventional) across all trial locations and seasons (2006 to 2008), and (D) comparing performance in (Maine and Oregon) across both seasons (fall and spring) and management systems (conventional and organic) and years (2006 to 2008).

For head weight, seven of eight trials showed significant $G$ $\times \mathrm{M}$ interaction, while all additional traits also showed significance in $G \times M$ interaction in five to seven of the eight trial combinations (data not shown).

\section{Comparison of Head Weight and Other Horticulture Traits over the Environments \\ Location, Season, Management System Overall}

Results across all S, L, and M system trials for Oregon showed a significantly higher overall head weight compared with Maine trials (Fig. 1A). Mean head weight of broccoli cultivars in the fall trials was significantly higher than in the spring trials for all $\mathrm{L}, \mathrm{S}$, and $\mathrm{M}$ combinations (fall $397 \mathrm{~g}$; spring $214 \mathrm{~g}$ ), (Fig. 1B). In the fall, the magnitude of the difference in head weight between Oregon (474 g) and Maine (321 g) were much larger than the difference in spring (Oregon $225 \mathrm{~g}$ versus Maine $202 \mathrm{~g}$ ). Organically produced broccoli (head weight overall 315 g) performed as well as conventionally produced broccoli (296 g) (Fig. 1C). Head weight across all organic trials had a wider range and greater variance among cultivars compared with conventional trials. An overview of location and season mean head weight are presented in Fig. 1D.

\section{Horticulture Trait Means}

Head diameter demonstrated the same pattern as head weight with broccoli from Oregon Fall trials having significantly larger head size than those from spring trials (Table 4). Days to maturity for broccoli cultivars grown in fall trials in Oregon (average $76 \mathrm{~d}$ ) were significantly longer than in spring (average $58 \mathrm{~d}$ ) trials, whereas in Maine the days to maturity for Fall (74 d) were comparable with Oregon, while the results of the spring trials for Maine (91 d) were longer than Oregon. Bead size ranking for Fall trials averaged 5.2 compared with 6.4 in spring trials in both locations, indicating larger beads were observed in Fall trials compared with spring in both locations and management systems. The same pattern was demonstrated for bead uniformity. Hollow stem had the highest incidence in Oregon fall, while Oregon spring and Maine trials were comparable. Plant height for broccoli cultivars grown in Oregon Fall trials were significantly taller than the Oregon spring trials and Maine trials across seasons, which agrees with the Oregon Fall head weight results (Table 4).

\section{Repeatability and Genetic Correlations: Organic versus Conventional}

The repeatabilities for head weight, head diameter, hollow stem, and overall quality ratings were higher for organic compared with conventional across trials (Table 5). For maturity, head color, and head surface, repeatability levels in organic were equal or near equal to those in conventional. For head shape, bead size, bead uniformity, and plant height, repeatabilities were higher in conventional compared with organic. The genetic correlations between organic and conventional for most traits were generally high, with the exception of bead uniformity, which showed the lowest genetic correlation (0.66). The ratio of correlated response to direct response for all traits was below 1, with the exception again of bead uniformity. When repeatabilities were calculated for $F_{1}$ hybrids only, repeatabilities and correlated response were smaller in most cases, but the trends were similar (with the exception of overall and head diameter).

\section{Comparison of Cultivar Rankings for Head Weight and Other Traits per Cultivar: Spearman's Rank Correlation}

We wanted to investigate the comparison between organic and conventional at the most fine-grained level, and looked at correlations between the genotypic means 
Table 4. Trait means of plant and head characteristics of 23 broccoli cultivars grown across four pair combinations of location (Maine or Oregon), season (fall or spring) two-years combined, and management system (conventional [C] organic [O]), 2006-2008.

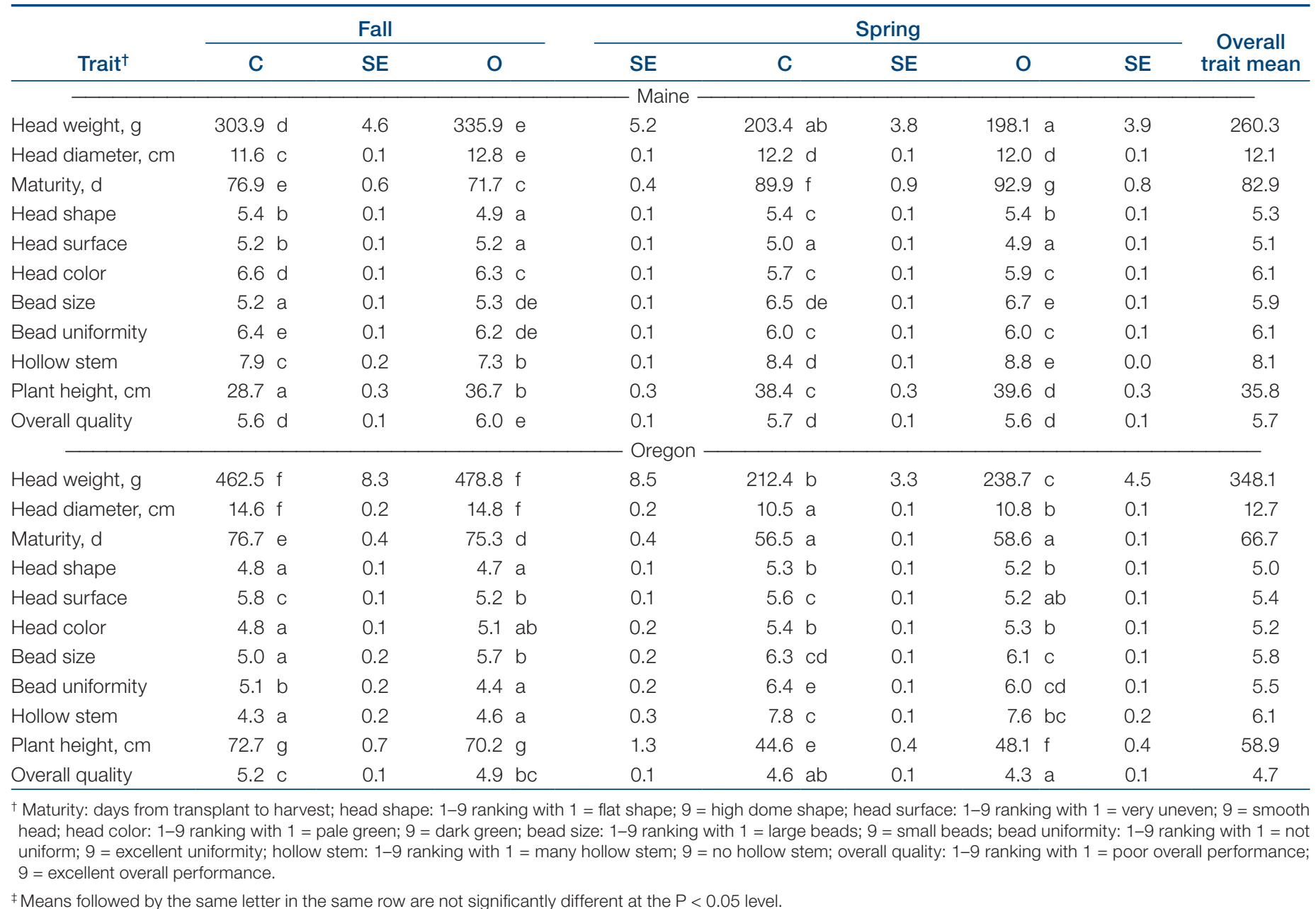

Table 5. Repeatabilities, genetic correlation $\left(r_{\mathrm{A}}\right)$, and ratio of correlated response to direct response $\left(\mathrm{CR}_{\text {org }} / \mathrm{R}_{\text {org }}\right)$ for broccoli horticulture traits comparing organic $(\mathrm{O})$ vs. conventional $(\mathrm{C})$ management systems over all trial season and location combinations (all cultivars and $\mathrm{F}_{1}$ hybrids only), 2006 to 2008.

\begin{tabular}{|c|c|c|c|c|c|c|c|c|}
\hline \multirow[b]{3}{*}{ Trait $^{\dagger}$} & \multicolumn{4}{|c|}{ All cultivars $\left(\mathrm{F}_{1} \mathrm{~s}, \mathrm{OPs} \text {, and inbreds }\right)^{\ddagger}$} & \multicolumn{4}{|c|}{$F_{1}$ hybrids only } \\
\hline & \multicolumn{2}{|c|}{ Repeatability } & \multirow[b]{2}{*}{$r_{\mathrm{A}}^{\S}$} & \multirow[b]{2}{*}{$\mathrm{CR}_{\text {org }} / \mathrm{R}_{\text {org }}$} & \multicolumn{2}{|c|}{ Repeatability } & \multirow[b]{2}{*}{$r_{\mathrm{A}}$} & \multirow[b]{2}{*}{$\mathrm{CR}_{\text {org }} / \mathrm{R}_{\text {org }}$} \\
\hline & $\mathrm{C}$ & $\mathrm{O}$ & & & C & $\mathrm{O}$ & & \\
\hline Head weight, $g$ & 0.78 & 0.85 & 0.91 & 0.87 & 0.60 & 0.68 & 0.73 & 0.69 \\
\hline Head diameter, $\mathrm{cm}$ & 0.61 & 0.75 & 0.81 & 0.73 & 0.14 & 0.00 & 0.22 & $>1$ \\
\hline Maturity, d & 0.79 & 0.80 & 0.98 & 0.97 & 0.81 & 0.86 & 0.98 & 0.95 \\
\hline Head shape & 0.47 & 0.37 & 0.73 & 0.83 & 0.72 & 0.69 & 0.87 & 0.89 \\
\hline Head surface & 0.81 & 0.77 & 0.90 & 0.92 & 0.46 & 0.53 & 0.85 & 0.79 \\
\hline Head color & 0.51 & 0.48 & 0.83 & 0.85 & 0.29 & 0.46 & 0.74 & 0.59 \\
\hline Bead size & 0.77 & 0.67 & 0.82 & 0.88 & 0.69 & 0.64 & 0.71 & 0.73 \\
\hline Bead uniformity & 0.24 & 0.03 & 0.66 & $>1$ & 0.09 & 0.23 & 0.65 & 0.42 \\
\hline Hollow stem & 0.40 & 0.57 & 0.84 & 0.70 & 0.49 & 0.67 & 0.88 & 0.75 \\
\hline Plant height, cm & 0.77 & 0.69 & 0.93 & 0.98 & 0.72 & 0.65 & 0.95 & 0.99 \\
\hline Overall quality & 0.72 & 0.77 & 0.89 & 0.86 & 0.17 & 0.48 & 0.63 & 0.38 \\
\hline
\end{tabular}

† Maturity: days from transplant to harvest; head shape: $1-9$ ranking with $1=$ flat shape; $9=$ high dome shape; head surface: $1-9$ ranking with $1=$ very uneven; $9=$ smooth head; head color: $1-9$ ranking with $1=$ pale green; $9=$ dark green; bead size: $1-9$ ranking with $1=$ large beads; $9=$ small beads; bead uniformity: $1-9$ ranking with $1=$ not uniform; 9 = excellent uniformity; hollow stem: $1-9$ ranking with 1 = many hollow stem; 9 = no hollow stem; overall quality: $1-9$ ranking with $1=$ poor overall performance; $9=$ excellent overall performance.

‡F1 = hybrid, $\mathrm{OP}=$ open pollinated.

$\S \mathrm{rA}$, average genetic correlation between conventional and organic production systems across locations. 
Table 6. Spearman's rank correlation for head weight between paired conventional and organic sites within a location, season, and year for the $F_{1}$ hybrid subset $(n=18)$ of broccoli cultivars.

\begin{tabular}{cccccc} 
& \multicolumn{2}{c}{ Maine } & & \multicolumn{2}{c}{ Oregon } \\
\cline { 2 - 3 } \cline { 5 - 6 } Year & Fall & Spring & & Fall & Spring \\
\hline 2006 & 0.51 & & & 0.42 & \\
2007 & 0.24 & 0.15 & & 0.33 & $0.69^{* * *}$ \\
2008 & & $0.69^{\star \star *}$ & & & $0.54^{*}$ \\
\hline
\end{tabular}

* Significant at $P<0.05$

*** Significant at $P<0.001$.

for the eight location by trialing period combinations. For head weight, conventional and organic genotypic means were highly correlated. However, when the $\mathrm{F}_{1}$ hybrid genotype class was analyzed separately (minus the OPs and inbred lines), most $M$ pairs were not significant, indicating change in rank between $\mathrm{M}$ in any given $\mathrm{Y}, \mathrm{L}$, or S. Genotype rank was significantly correlated between management systems in Maine spring 2008, and Oregon spring 2007 and 2008, but genotypic rank was not correlated in fall environments (Table 6).

We visualized the rank correlations of the individual cultivars between conventional and organic conditions at the location by season trial level in Table 7 . The ranking of cultivars for head weight between locations and seasons differed by cultivar, cultivar type, and maturity classification. Between the paired management system trials, some cultivars showed the same ranking, while others varied in rank. The OP cultivars consistently ranked at the bottom, while a group of $F_{1}$ cultivars displayed the greatest head weight across management systems.

In the Maine trials, all cultivars from organic trials outperformed those grown in conventional trials for head weight. In the Fall trials, four of the five top-ranking cultivars were the same between the organic and conventional trials ('Packman', 'Fiesta', 'Everest' and 'Green Goliath'), see Table 7. 'Green Magic' was the top performing cultivar in organic, but ranked 10th in conventional, with a significant head weight difference between Management systems. In the Maine organic spring trials there were more rank changes. The top two performing cultivars (Fiesta and Green Magic) were the seventh and eighth ranked cultivars in conventional, while 'Imperial' ranked third in both systems. The best performing cultivars under conventional ('Marathon', 'Nutribud', 'Early Green') did not perform comparatively well under organic (rank 11, 12, and 18, respectively)

The results for the Oregon Fall trials for head weight indicated that three of the five top performing varieties in both organic and conventional systems were the same: Green Magic, 'Maximo' and 'Batavia'), see Table 7. All three cultivars produced higher yields in the organic trials compared with the conventionally paired trial. Imperial ranked No. 1 in conventional, while it ranked No. 6 in organic, and similar to the Maine trials, Marathon ranked high in Oregon organic (No. 4) and much lower (No. 13) in conventional (significantly different than top two cultivars, Imperial and Green Magic), with a significant head weight difference in cultivar performance between management systems. Conventional 5th and 6th ranked cultivars, 'Belstar' and 'B1 10', dropped in rank to 9th and 11th in organic, respectively (significantly different from Green Magic, but not other cultivars in organic).

\section{Stability of Genotype Performance}

The results of the stability analysis of a cultivars capacity to perform comparably across trial locations, and seasons in the different management systems for head weight indicated that under both management systems, Belstar, Batavia, and Green Magic were similar across environments (Fig. 2A, 2B). 'Arcadia' was highly stable across organic trials (ranked 5th), but less stable across conventional trials (ranked 11th). Because we were interested in the broccoli cultivars that provide both an acceptable yield and displayed stability across environments, we combined the analysis of head weight ranking with stability across environments, using $300 \mathrm{~g}$ as a minimum threshold for weight and $15 \mathrm{~g}^{2}$ as a maximum threshold for stability (Fig. 2A, 2B). In that quadrant the cultivars Batavia, Belstar, and Green Magic had the highest combined stability and head weight across both management systems. In the top group of most productive and stable cultivars, B1 10 appeared in conventional trials (Fig. 2A), and Arcadia and Everest in the organic trials (Fig. 2B). The $\mathrm{OP}$ and inbred cultivars 'OSU OP', Nutribud, Early Green (OPs), and USVL 048 and 093 (inbreds) had the lowest head weight and least stability across trials. In the combined head weight and stability analysis, the $\mathrm{F}_{1}$ hybrid cultivar 'Diplomat' was in the bottom-performing group overall.

\section{Correlation between Horticulture Traits and Grouping of Cultivars by Management System Correlations among Horticulture Traits}

The correlation analysis between genotypic means across trials, separately for organic and conventional management system, shows that head weight was positively and highly correlated with head size, bead size, bead uniformity (conventional only), and overall quality (Table 8). Conversely, head weight was negatively correlated with head color, but it was not significant. There was a significant positive correlation for head shape and bead size in both systems. Overall quality was highly correlated across both management systems for head weight, head diameter, bead uniformity, head surface, and bead uniformity, and in conventional systems for head shape and bead size. 
Table 7. Ranking of average head weight $(\mathrm{g})$ of 23 cultivars of broccoli grown under organic and conventional conditions in Maine and Oregon in two seasons (fall and spring) from 2006 to 2008.

\begin{tabular}{|c|c|c|c|c|c|c|c|c|c|c|c|}
\hline \multicolumn{6}{|c|}{ Fall 2006-2007 } & \multicolumn{6}{|c|}{ Spring 2007-2008 } \\
\hline Rank & \multicolumn{2}{|c|}{ Conventional } & \multicolumn{2}{|r|}{ Organic } & Rank & Rank & \multicolumn{2}{|c|}{ Conventional } & \multicolumn{2}{|r|}{ Organic } & \multirow{2}{*}{$\begin{array}{c}\text { Rank } \\
- \\
1\end{array}$} \\
\hline 1 & Packman & 369.1 & 431.6 & Green Magic* & 1 & 1 & Marathon & 243.2 & 251.2 & Fiesta & \\
\hline 2 & Fiesta & 365.8 & 424.5 & Packman & 2 & 2 & Nutribud & 243.0 & 251.0 & Green Magic & 2 \\
\hline 3 & Everest & 360.6 & 400.8 & Fiesta & 3 & 3 & Imperial & 240.6 & 247.1 & Imperial & 3 \\
\hline 4 & Green Goliath & 353.2 & 398.6 & Everest & 4 & 4 & Early Green & 240.0 & 240.5 & B1 10 & 4 \\
\hline 5 & Belstar & 346.4 & 397.7 & Green Goliath & 5 & 5 & Batavia & 232.2 & 228.1 & Belstar & 5 \\
\hline 6 & Batavia & 344.1 & 392.9 & Batavia & 6 & 6 & Belstar & 226.6 & 222.0 & Batavia & 6 \\
\hline 7 & Diplomat & 335.9 & 368.4 & Belstar & 7 & 7 & Fiesta & 224.2 & 217.0 & Arcadia & 7 \\
\hline 8 & Patriot & 334.6 & 367.7 & B1 10 & 8 & 8 & Green Magic & 219.1 & 212.1 & Gypsy & 8 \\
\hline 9 & B1 10 & 324.9 & 361.7 & Marathon & 9 & 9 & B1 10 & 218.7 & 207.4 & Green Goliath & 9 \\
\hline 10 & Green Magic & 324.5 & 352.9 & Maximo & 10 & 10 & Maximo & 215.0 & 205.3 & Maximo & 10 \\
\hline 11 & Nutribud & 316.6 & 352.8 & Patron & 11 & 11 & Premium Crop & 211.5 & 204.9 & Marathon & 11 \\
\hline 12 & Patron & 309.2 & 333.6 & Patriot & 12 & 12 & OSU OP & 202.6 & 202.5 & Nutribud & 12 \\
\hline 13 & Marathon & 302.1 & 332.8 & Early Green & 13 & 13 & Patriot & 200.3 & 201.7 & Patriot & 13 \\
\hline 14 & Maximo & 291.9 & 324.9 & Premium Crop & 14 & 14 & Green Goliath & 199.1 & 195.3 & OSU OP & 14 \\
\hline 15 & Gypsy & 272.6 & 322.0 & Gypsy & 15 & 15 & Packman & 190.3 & 191.1 & Premium Crop & 15 \\
\hline 16 & Premium Crop & 270.8 & 317.6 & Imperial & 16 & 16 & Beaumont & 189.1 & 185.5 & Beaumont & 16 \\
\hline 17 & Early Green & 264.8 & 307.5 & Arcadia & 17 & 17 & Diplomat & 187.5 & 180.0 & Diplomat & 17 \\
\hline 18 & Imperial & 253.4 & 298.5 & Nutribud & 18 & 18 & Everest & 182.3 & 167.4 & Early Green & 18 \\
\hline 19 & Arcadia & 252.4 & 288.5 & Diplomat & 19 & 19 & Arcadia & 180.5 & 167.1 & Packman & 19 \\
\hline 20 & USVL 093 & 232.2 & 265.5 & USVL 048 & 20 & 20 & Gypsy & 177.6 & 166.3 & Patron & 20 \\
\hline 21 & OSU OP & 211.7 & 258.0 & Beaumont & 21 & 21 & Patron & 163.9 & 157.0 & Everest & 21 \\
\hline 22 & USVL 048 & 200.3 & 219.3 & USVL 093 & 22 & 22 & USVL 093 & 156.5 & 146.8 & USVL 048 & 22 \\
\hline 23 & Beaumont & 110.7 & 218.3 & OSU OP & 23 & 23 & USVL 048 & 139.0 & 103.3 & USVL 093 & 23 \\
\hline 1 & Imperial & 604.6 & 685.8 & Green Magic & 1 & 1 & Batavia & 292.7 & 348.3 & Batavia & 1 \\
\hline 2 & Green Magic & 585.4 & 636.4 & Maximo & 2 & 2 & Green Goliath & 271.9 & 321.1 & Green Goliath & 2 \\
\hline 3 & Maximo & 580.7 & 624.9 & Batavia & 3 & 3 & Belstar & 270.2 & 311.2 & Maximo & 3 \\
\hline 4 & Batavia & 571.6 & 608.0 & Marathon* & 4 & 4 & B1 10 & 265.2 & 308.6 & Marathon & 4 \\
\hline 5 & B1 10 & 554.4 & 565.7 & Patron & 5 & 5 & Maximo & 264.8 & 305.0 & Fiesta & 5 \\
\hline 6 & Belstar & 552.8 & 561.1 & Imperial & 6 & 6 & Imperial & 259.8 & 300.9 & Gypsy & 6 \\
\hline 7 & Green Goliath & 535.5 & 559.5 & Green Goliath & 7 & 7 & Fiesta & 241.0 & 299.3 & Patron & 7 \\
\hline 8 & Everest & 522.2 & 538.8 & B1 10 & 8 & 8 & USVL 048 & 240.0 & 290.5 & Patriot & 8 \\
\hline 9 & Patron & 521.7 & 526.6 & Belstar & 9 & 9 & Patron & 235.2 & 290.0 & B1 10 & 9 \\
\hline 10 & Arcadia & 499.6 & 517.7 & Beaumont & 10 & 10 & Gypsy & 231.5 & 289.2 & Green Magic & 10 \\
\hline 11 & Gypsy & 493.7 & 516.7 & Gypsy & 11 & 11 & Patriot & 218.5 & 284.7 & Belstar & 11 \\
\hline 12 & Diplomat & 490.7 & 494.5 & Everest & 12 & 12 & Marathon & 217.2 & 235.4 & Arcadia & 12 \\
\hline 13 & Marathon & 480.0 & 486.2 & Packman & 13 & 13 & Beaumont & 216.2 & 223.9 & Premium Crop & 13 \\
\hline 14 & Fiesta & 474.8 & 485.5 & Fiesta & 14 & 14 & Arcadia & 211.0 & 221.1 & USVL 048 & 14 \\
\hline 15 & Patriot & 459.2 & 481.3 & Arcadia & 15 & 15 & Green Magic & 202.6 & 220.0 & Imperial & 15 \\
\hline 16 & Beaumont & 449.4 & 467.6 & Patriot & 16 & 16 & Premium Crop & 197.2 & 208.7 & Diplomat & 16 \\
\hline 17 & Packman & 421.7 & 430.8 & Premium Crop & 17 & 17 & Everest & 191.8 & 198.5 & Packman & 17 \\
\hline 18 & Premium Crop & 390.9 & 428.6 & Diplomat & 18 & 18 & Nutribud & 176.3 & 195.0 & Beaumont & 18 \\
\hline 19 & USVL 048 & 380.6 & 357.8 & USVL 048 & 19 & 19 & Diplomat & 169.6 & 162.0 & Everest & 19 \\
\hline 20 & Nutribud & 343.9 & 302.8 & Early Green & 20 & 20 & Packman & 151.3 & 138.9 & Nutribud & 20 \\
\hline 21 & OSU OP & 265.4 & 267.6 & Nutribud & 21 & 21 & Early Green & 146.2 & 127.4 & Early Green & 2 \\
\hline 22 & Early Green & 242.3 & 217.4 & USVL 093 & 22 & 22 & OSU OP & 111.1 & 107.5 & USVL 093 & 22 \\
\hline 23 & USVL 093 & 235.1 & 213.5 & OSU OP & 23 & 23 & USVL 093 & 104.1 & 106.6 & OSU OP & 23 \\
\hline
\end{tabular}

* Significant at the $P<0.05$ level.

\section{DISCUSSION}

\section{Relative importance of Management System, Location, and Season}

Overall, our trials demonstrated that location and season, not management system, are the largest source of environmental variation in broccoli cultivar performance. The significantly higher broccoli head weight from the Oregon trials compared with the Maine trials in both seasons, as well as the overall higher broccoli head weight across all trials in the fall compared with the spring, supported these findings. Higher head weight overall in the Oregon field trials could be explained by the climatic differences 


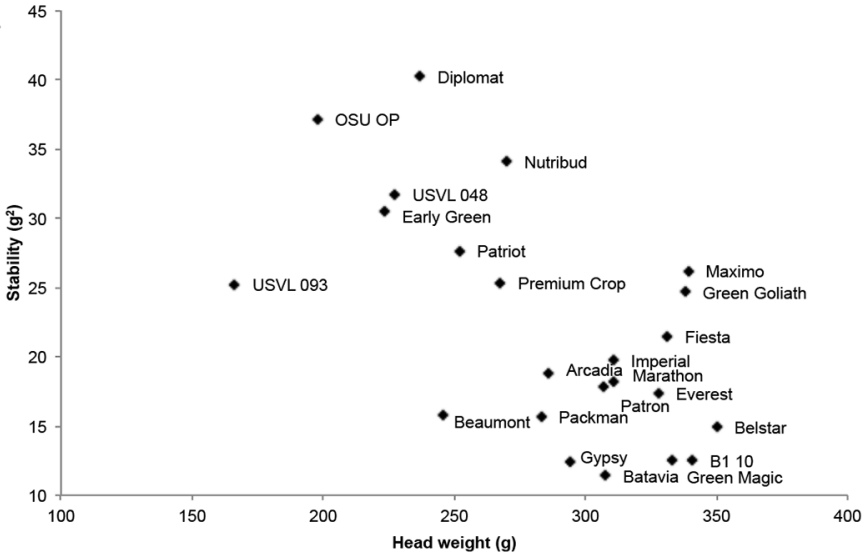

B

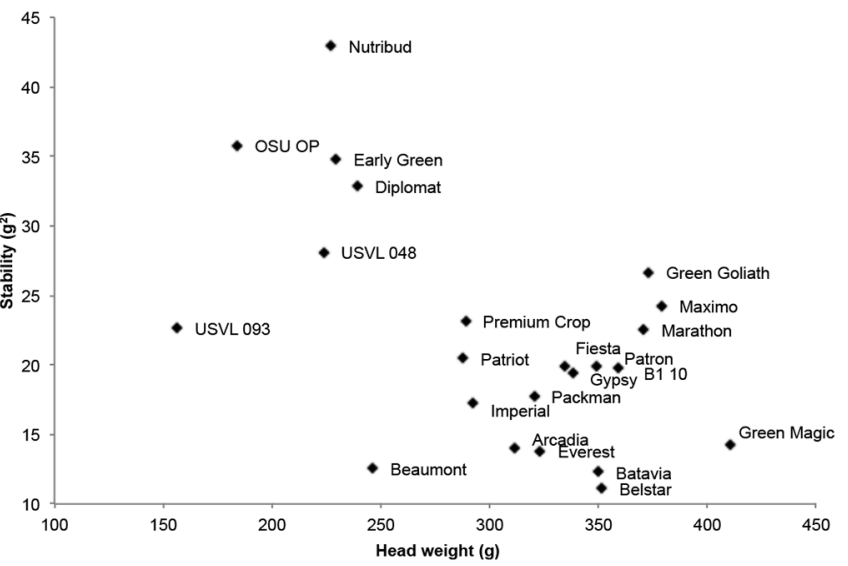

Figure 2. Broccoli cultivar (in)stability, expressed as the cultivar variance $\left(\mathrm{g}^{2}\right)$, plotted against mean head weight (g) across trials in Oregon and Maine, across seasons (fall and spring), 2006 to 2008. (A) Conventional, and (B) organic management systems.

Table 8. Genetic correlation of broccoli horticulture traits across organic and conventional trials (upper right of diagonal, organic; lower left of diagonal, conventional).

\begin{tabular}{|c|c|c|c|c|c|c|c|c|c|c|c|}
\hline & $\begin{array}{l}\text { Head } \\
\text { weight }\end{array}$ & $\begin{array}{l}\text { Head } \\
\text { diameter }\end{array}$ & $\begin{array}{l}\text { Hollow } \\
\text { stem }\end{array}$ & Maturity & $\begin{array}{l}\text { Head } \\
\text { color }\end{array}$ & $\begin{array}{l}\text { Head } \\
\text { shape }\end{array}$ & $\begin{array}{l}\text { Bead } \\
\text { size }\end{array}$ & $\begin{array}{c}\text { Bead } \\
\text { uniformity }\end{array}$ & $\begin{array}{l}\text { Head } \\
\text { surface }\end{array}$ & $\begin{array}{l}\text { Plant } \\
\text { height }\end{array}$ & $\begin{array}{l}\text { Overall } \\
\text { quality }\end{array}$ \\
\hline Head weight & & 0.83 & $-0.18^{\dagger}$ & 0.30 & -0.25 & 0.32 & 0.49 & 0.38 & 0.17 & 0.32 & 0.74 \\
\hline Head diameter & 0.76 & & -0.16 & -0.10 & -0.20 & -0.12 & 0.33 & 0.31 & -0.09 & 0.54 & 0.73 \\
\hline Hollow stem & -0.09 & -0.05 & & 0.01 & -0.02 & 0.20 & -0.01 & 0.12 & 0.07 & -0.21 & -0.03 \\
\hline Maturity & 0.39 & -0.06 & 0.16 & & -0.28 & 0.60 & 0.61 & -0.09 & 0.07 & -0.22 & -0.04 \\
\hline Head color & -0.31 & -0.26 & -0.32 & -0.29 & & 0.15 & 0.02 & 0.29 & 0.15 & 0.32 & 0.16 \\
\hline Head shape & 0.42 & -0.08 & 0.22 & 0.65 & 0.12 & & 0.54 & 0.39 & 0.61 & -0.10 & 0.37 \\
\hline Bead size & 0.66 & 0.29 & 0.10 & 0.66 & -0.25 & 0.64 & & 0.30 & -0.04 & 0.13 & 0.39 \\
\hline Bead uniformity & 0.46 & 0.46 & -0.16 & -0.16 & 0.06 & 0.12 & 0.35 & & 0.42 & 0.32 & 0.73 \\
\hline Head surface & 0.13 & -0.02 & 0.25 & 0.11 & 0.33 & 0.59 & 0.05 & 0.25 & & 0.14 & 0.42 \\
\hline Plant height & 0.19 & 0.41 & -0.30 & -0.24 & 0.35 & -0.11 & 0.12 & 0.64 & 0.09 & & 0.63 \\
\hline Overall quality & 0.64 & 0.55 & -0.10 & 0.09 & 0.21 & 0.46 & 0.53 & 0.69 & 0.52 & 0.61 & \\
\hline
\end{tabular}

'Values $\leq|0.40|$ are not significantly different from zero at the $P<0.05$ level.

between Oregon and Maine, with Oregon having more GDDs than Maine in both fall season trial years (Table 2). For many traits, management system contributed only to variation at the three- and four-way interaction level, and these interactions constituted a large portion of the total variance in the model. Thus, genotype by management systems interactions did occur, but there were no overarching effects of management system apparent across locations and seasons.

One of the reasons for only the small magnitude of the management system relative to other environmental factors on head weight could be the fact that, on average over all trials, this trait did not significantly differ when cultivars were grown under organic and conventional conditions, even though variances differed. This is in contrast with much of the literature (e.g., de Ponti et al., 2012; Seufert et al., 2012) who, after reviewing comparative studies, concluded overall that organic yields were on average lower (reduction of 5 to 34\%) compared with conventional. Their reviews suggested that, when farms have been managed organically over a long period of time with consistent soil building practices, soil fertility increases due to higher levels of organic matter and improved water holding capacity and increased POM, can produce higher or comparable yields to conventionally produced crops. When comparing the soil quality of the Oregon and Maine trial locations, the soils at both of the conventional trial sites had higher levels of immediately available $\mathrm{N}$ compared with the organic sites at the time of trial implementation, but had lower POM levels, indicating that their long-term available $\mathrm{N}$ was less compared with the organic sites (Table 2). Our results in Oregon and Maine demonstrated that organic is not per se lower yielding compared with conventional. Broccoli grown under organic conditions in the spring, however, may be at more of a disadvantage due to slower $\mathrm{N}$ mineralization rates under cooler temperatures resulting in lower yields than conventional. This was shown in trials in Oregon where there were 100 fewer GDD in Spring 2008 compared with 2007, and where organic yields were lower than under conventional conditions (Table 2).

Despite comparable mean head weights between organic and conventional growing conditions, the overall range in head weight across cultivars was greater in 
organic than conventional across all trials, (Fig. 1C) which represents a larger variance in organic compared with conventional. This difference in head weight variance was even more pronounced in the fall trials compared with the spring trials (Fig. 1D). Ceccarelli $(1994,1996)$, in discussing barley (Hordeum vulgare L.) breeding for marginal, low input, and drought-prone environments indicated that such environments can be heterogeneous, and genetic variance can be greater compared with more homogeneous high input low stressed environments, and that by breeding solely under high input conditions, an opportunity to exploit genetic differences at lower input levels can be lost. While our organic trial locations were not necessarily representative of the type of abiotic stresses described by Ceccarelli, the locations did exhibit the unique stresses of an organically managed heterogeneous environment. Such characteristics that define an organic management system and were representative of our broccoli trials included slow release of nutrients, plant defense against insect predation (e.g., flea beetles and aphids) without insecticides, and the additional weed pressure typically found in an organic management system without the use of synthetic herbicides. Ceccarelli proposes also that the environment of selection affects the pattern of responses of genotypes to varying environmental conditions. Repeated cycles of selection in a given type of environment will reduce the frequency of lines specifically adapted to other environments. Most of the cultivars evaluated in our trials were commercial $F_{1}$ hybrids originally selected for and used in high input conventional agriculture systems, while the remainder were OPs selected under organic or low input conditions and inbreds selected in South Carolina. The combination of $F_{1}$ hybrids and OPs in the same trial may explain the broader range of variation observed for genotype performance when grown under organic conditions. Another aspect to be taken into account is that, if hybrids alone are considered, the range of variation is narrowed, as demonstrated in Table 6.

Our third major finding related to management system is that only at the three- and four-way interaction level did management system play a significant role. As such, it appeared that under our trial conditions, there were $G \times M$ interactions within each trial combination, but that organic management did not have a large impact on a seasonal or regional basis. In other words, there do not appear to be factors associated with organic systems that transcend regions and seasons, rather, each environment is different, and differences between organic and conventional systems are apparent on a local trial level. This observation is supported by the fact that when data were analyzed within region and season, most paired trials at the individual location, season, and year level had $G \times$ M system interactions.

\section{Cultivar Ranking and Stability in Management Systems}

Our trial results demonstrated that, across all locations and seasons, overall cultivar rankings were comparable (with some exceptions) for head weight between organic and conventional trials. Østergård et al. (2005) proposed that not only yield as such, but also yield stability across years and seasons are important breeding objectives for organic conditions. Batavia, Belstar, and Green Magic had the highest combined head weight and head weight stability in both management systems, while Arcadia was one of the top-performing cultivars in organic, but not in conventional trials. Not all cultivars that performed well in head weight were stable, such as Maximo. These examples demonstrate that some cultivars may be more tolerant to abiotic and biotic stress than others, and therefore more suitable for organic management systems. A strong positive correlation of top-performing cultivars between management systems was also found by Burger et al. (2008) for maize, who recommended as a result of these findings that cultivar performance under conventional conditions could provide a good prediction for the average cultivar performance under organic conditions in a breeding program. They also recommended that the use of organic test sites would increase the chances of identifying broadly adapted genotypes when aiming at cultivars for both systems.

To further examine the question of whether differences in ranking at the individual paired conventional and organic sites were significant, we performed Spearman's rank correlation on cultivar performance between paired conventional and organic environments. Correlation coefficients were large and statistically significant, as would be expected when mean genotype ranking was similar between management systems (data not shown). However, when correlation was performed on $\mathrm{F}_{1}$ s only (leaving out the inherently lower-yielding OPs and inbreds), significant correlation was observed in the trial combinations for Maine spring 2008, and Oregon spring 2007 and 2008, but not the other five trial combinations (Table 6). It is apparent that the significant correlations observed on the full set of cultivars was a function of hybrids always being higher-yielding than OPs and inbreds, but a much weaker association was revealed within the hybrid subgroup. The weak correlation among hybrids is in agreement with the crossover interaction that was observed at a local level between management systems described above (Table 7). Przystalski et al. (2008) analyzed performance of cereals grown under organic and conventional systems in multiple locations, and determined that despite high overall genetic correlation for yield and associated traits, there were exceptions on the individual cultivar ranking level that could be relevant to the selection process. For example, a cultivar that produced an average yield under conventional conditions could perform among the top 
under organic conditions due to better weed competitive ability. In order not to overlook the best performing cultivars for organic management systems, they advised combining the cultivar ranking results from trials from both management systems (see also Reid et al., 2009, 2011).

In our trials, the OP cultivars were the lowest yielding and least stable across all trials. The small group of OPs in our trials tended to be early maturing and demonstrated a narrow harvest window at prime quality, which could have contributed to their lack of resilience to environmental variation. Duvick (2009) found that the heterosis in maize hybrids contributed to their overall vigor under stress conditions. However, the research of Ceccarelli (1996) and Pswarayi et al. (2008) in the case of barley indicated that modern cultivars were adapted to low stress, high-yielding environments and did not always perform favorably in higher stress, marginal conditions. In the case of our trials, however, the organic management conditions were not necessarily low-input stress conditions in the strictest sense, as mean head weights were comparable with conventional, and therefore high-ranking hybrids were shared across environments, with the exception of some that dropped their high ranking under organic conditions. We therefore must stress that we anticipate that results could be different when growing conditions are less favorable for crop growth.

\section{Repeatability as Affected by Management Systems}

Lammerts van Bueren et al. (2002) described organic growing conditions as heterogeneous and sometimes lower-input environments compared with conventionally managed production environments where high levels of readily available $\mathrm{N}$ can mask variation in soil quality conditions. Higher variability in growing conditions under organic conditions may cause increased macro- and micro-environmental variance relative to the genotypic component, and result in lower heritabilities compared with more controlled conditions in high-input conventional farming conditions. In the present study, we were able to estimate the proportion of the genotypic variance relative to phenotypic variance, but because we did not have a genetically structured breeding population, could only estimate repeatability rather than broad sense heritability. The argument commonly used to support selecting in optimal environments is that heritabilities are higher in high input environments compared with poor environments (Ceccarelli, 1994, 1996). In our trials, repeatabilities for head weight, head diameter, hollow stem, and overall quality were higher for organic compared with conventional, while for the traits of maturity, head color, and head surface, repeatability levels between management systems were equal or near equal. It is recognized that these coefficients combine additive and nonadditive genetic variance, and it would be anticipated that they would be much lower if the additive component was partitioned out. For the traits of head shape, bead size, and bead uniformity, repeatabilities were higher in conventional compared with organic, which could be explained by a more variable organic management environment. The traits with repeatabilities larger or equal in organic systems were those generally associated with growth and productivity, and probably under similar genetic control, whereas those with repeatibilities lower in organic compared with conventional are probably under separate genetic control. Higher heritabilities under organic conditions were also found by Burger et al. (2008) and Goldstein et al. (2012) for maize and for faba bean (Vicia faba L.; Link and Ghaouti, 2012). They supported their findings with the following justifications, which can also explain our results: (i) with heterogeneous soils found in organic management systems, the precision of experiments may be more impaired under stress (slow nutrient release) than under conventional high input conditions; (ii) genetic variance may be greater under stress conditions than nonstress conditions, and (iii) the high genetic variance in organic trials compensated for the high experimental error which produced comparable heritabilities between organic and conventional trials.

Trait repeatabilities alone are not sufficient to determine the optimum selection environment. Both estimates of genetic variance and repeatabilities are useful in predicting the response to selection in organic and conventional management systems. Estimates of the genetic correlation between performance of traits in the organic and conventional management systems is an indicator for the extent of $\mathrm{G} \times \mathrm{M}$ interaction. In our broccoli trials, the genetic correlations between organic and conventional trials for the traits head weight, maturity, head shape, and plant height were high $(>0.90)$, indicating that a differential response of the genotypes to the two management systems was largely absent. The ratio of correlated response to direct response for all traits was close to but below 1.0, with the exception of bead uniformity. This would imply that, in most cases, selection directly in an organic environment could result in more rapid genetic gain than indirect selection in a conventional environment, but because most repeatabilities were close to 1.0, indirect selection in a conventional environment would be nearly as effective as direct selection in an organic system. Also in our trials, we found larger genetic variances (broader minimum-maximum ranges) compared with results under conventional management.

\section{Breeding Broccoli for Organic Systems}

Determining whether broccoli cultivar development could better take place under organic or conventional management systems to develop cultivars optimized for organic agriculture is a complex proposition. Breeding in 
the target environment is most effective for organic systems, where $\mathrm{G} \times \mathrm{E}$ interaction, genetic diversity, and trait heritability are all taken into account (see e.g., Wolfe et al., 2008). Driven by the need for efficiency, commercial broccoli breeders often aim to reduce $\mathrm{G} \times \mathrm{E}$ interactions by selecting cultivars that are broadly adapted to the range of their target environments. However, from our data, location and season and their interactions were the primary sources of variation identified for broccoli head weight and the other horticultural traits studied. This is supported by our observations that the general locationand season-specific trend for head weight interacted with the cultivar's maturity class designation, where mid-tolate season cultivars were the highest ranking in Oregon in the fall, while in Maine early to midseason cultivars were the highest ranking. In the spring, best-performing cultivars in both Maine and Oregon were in the mid- to late-season maturing class. When comparing cultivar performance between seasons and locations, we observed that the best performing early to midseason cultivars in spring trials and the mid- to late-season cultivars in fall trials for Oregon were a different group of cultivars than those in Maine of the same maturity class.

Greater heterogeneity in organic management systems and $\mathrm{G} \times \mathrm{M}$ crossover interaction observed on a local scale supports the idea that direct selection (under organic management) of cultivars for organic agriculture would benefit from evaluation in organic systems, particularly if the intent of the breeder is to develop cultivars that support local adaptation. Annicchiarico et al. (2012) found that the performance of lucerne (Medicago sativa L.) populations bred in the location of intended use were better performers on organic farms in northern Italy compared with cultivars that were bred outside of the intended region. Annicchiarico et al. (2010) also found that, when comparing $\mathrm{G} \times \mathrm{M}$ to $\mathrm{G} \times \mathrm{L}$, the effect of wheat selected for a specific bioregion outweighed the effect of breeding for management system for direct selection of yield. Specific to broccoli, Crisp and Gray (1984) reported that, to develop cultivars for a specific season, populations from different maturity groups should be used to take advantage of high heritability in heading characteristics, head color, and time of maturity.

The stability between the organic and conventional trials across most trials, and comparable heritability between systems for most traits, would suggest that selection for broccoli for organic systems would best be performed under organic conditions. Lorenzana and Bernardo (2008) suggest that breeding for adaptation to organic production environments could be conducted under conventional conditions due to high correlations, with the caveat that advanced breeding lines be tested under organic conditions for less heritable traits such as yield. However, in our trials, there was significant crossover interaction at the individual trial level, as well as low rank correlation when genotypic classes were separated in the ranking analysis. Considering these findings (and without taking costs into account), a separate organic regional, seasonal breeding program for broccoli can be effective. This is further supported by the fact that the ratio of correlated response to direct response in our trials for most traits was close to but below 1.0, implying that selection directly in an organic environment could result in more rapid genetic gain than indirect selection in a conventional environment.

The large genotype variance observed in our organic trials relative to conventional trials indicated that the potential for breeding within an organic system may benefit cultivar development for both management systems. Because organic management systems do not use synthetic fertilizers and pesticides, the potential for a breeder to observe and select parent lines for $\mathrm{N}$ use efficiency, disease resistance, and vigor under organic systems may bring benefits to the breeding program. Because of the different management practices, locations, and seasonal differences in organic farming across the United States, such screening could provide additional information about breeding line performance, and support in determining which lines are most stable across environments and in organic conditions. Burger et al. (2008) found with maize selection, that trialing advanced lines under conventional management after determining superior lines selected in organic systems could also enhance conventional breeding, as lines that tolerate stress in an organic management system may carry this performance over to stress conditions that can also occur under conventional systems.

We want to stress that our study included predominantly modern broccoli cultivars selected for broad adaptability in conventional production systems, which does not fully show the potential of selection in breeding populations under organic management. Kirk et al. (2012) and Reid et al. (2011) both reported that direct selection in organically managed field conditions for genotypes targeted for organic agriculture offered advantages over indirect selection in conventionally managed field conditions for spring wheat because they found that breeding populations selected in organic environments had higher yields when grown organically, compared with conventionally selected populations that did not perform comparatively well. We therefore recommend that, for further studies, early generation broccoli breeding lines, and/or populations be compared to attain a better prediction of genetic correlations for organic, and to explore potential genetic changes that may occur when broccoli breeding lines are bred in the target environment from inception. 


\section{Acknowledgments}

For the Oregon trials, the authors wish to thank the organic growers Jolene Jebbia and John Eveland at Gathering Together Farm for providing the location and support for the organic broccoli trials. We deeply appreciate the efforts of Deborah Kean, Faculty Research Assistant at the Oregon State University Research Station, and the students Hank Keogh, Shawna Zimmerman, Miles Barrett, and Jennifer Fielder for support in data collection of the field trials. For the Maine trials, the authors wish to thank the students Heather Bryant, Chris Hillard, and Greg Koller for support in data collection of the field trials. We also thank the University of Maine Highmoor Farm Superintendent, Dr. David Handley University of Maine Cooperative Extension. For the soil analysis, we thank Dr. Michelle Wander from the University of Illinois, Urbana, and her students. At Wageningen University, we thank Paul Keizers and Dr. Chris Maliepaard for support with the statistical analysis. We thank Carl Jones for his valuable input on iterations of this research paper and Ric Gaudet for support in data organization. We thank Wageningen University, Oregon State University, Seeds of Change and Vitalis Organic Seeds, Enza Zaden for their financial and in-kind support in making this research project possible.

\section{References}

Annicchiarico, P., E. Chiapparino, and M. Perenzin. 2010. Response of common wheat varieties to organic and conventional production systems across Italian locations, and implications for selection. Field Crops Res. 116:230-238. doi:10.1016/j.fcr.2009.12.012

Annicchiarico, L., L. Pecetti, and R. Torricelli. 2012. Impact of landrace germplasm, non-conventional habit and regional cultivar selection on forage and seed yield of organically grown lucerne in Italy. J. Agric. Sci. 150:345-355. doi:10.1017/ S0021859611000700

Baresel, J.P., G. Zimmermann, and H.J. Reents. 2008. Effects of genotype and environment on $\mathrm{N}$ uptake and $\mathrm{N}$ partition in organically grown winter wheat (Triticum aestivum L.) in Germany. Euphytica 163:347-354. doi:10.1007/s10681-008-9718-1

Burger, H., M. Schloen, W. Schmidt, and H.H. Geiger. 2008. Quantitative genetic studies on breeding maize for adaptation to organic farming. Euphytica 163:501-510. doi:10.1007/ s10681-008-9723-4

Ceccarelli, S. 1994. Specific adaptation and breeding for marginal conditions. Euphytica 77:205-219. doi:10.1007/BF02262633

Ceccarelli, S. 1996. Adaptation to low/high input cultivation. Euphytica 92:203-214. doi:10.1007/BF00022846

Crisp, P., and A.R. Gray. 1984. Breeding old and new forms of purple heading broccoli. Cruciferae Newslett. 9:17-18.

de Ponti, T., B. Rijk, and M.K. van Ittersum. 2012. The crop yield gap between organic and conventional agriculture. Agric. Syst. 108:1-9. doi:10.1016/j.agsy.2011.12.004

Dillon, M., and K. Hubbard. 2011. State of organic seed 2011. Available at: http://seedalliance.org/uploads/publications/ SOS_2011_Report.pdf/ (verified 21 Apr. 2014). Organic Seed Alliance, Port Townsend, WA.

Duvick, D.N. 2009. Selection methods. Part 3: Hybrid breeding. In: S. Ceccarelli et al., editors, Plant breeding and farmer participation. FAO, Rome. p. 229-258.
Falconer, D.S., and T.F.C. Mackay. 1996. Introduction to quantitative genetics. Pearson Education Limited, Essex, UK.

Farnham, M.W., and T. Bjorkman. 2011a. Evaluation of experimental broccoli hybrids developed for summer management in the eastern United States. HortScience 46(6):858-863.

Farnham, M.W., and T. Bjorkman. 2011b. Breeding vegetables adapted to high temperatures: A case study with broccoli. HortScience 46(8):193-197.

Goldstein, W., W. Schmidt, H. Burger, M. Messmer, L.M. Pollak, M.E. Smith, M.M. Goodman, F.J. Kutka, and R.C. Pratt. 2012. Maize: Breeding and field testing for organic farmers. In: E.T. Lammerts et al., editors, Organic crop breeding. WileyBlackwell. John Wiley \& Sons, West Sussex, UK. p. 175-189.

Heather, D.W., J.B. Sieczka, M.H. Dickson, and D.W. Wolfe. 1992. Heat tolerance and holding ability in broccoli. J. Am. Soc. Hortic. Sci. 117(6):887-892.

Kirk, A.P., S.L. Fox, and M.H. Entz. 2012. Comparison of organic and conventional selection environments for spring wheat. Plant Breed. 131:687-694. doi:10.1111/j.1439-0523.2012.02006.x

Koutis, K., A.G. Mavromatis, D. Baxevanos, and M. KousikaSotiriou. 2012. Multi environmental evaluation of wheat landraces by GGE BiPlot analysis for organic breeding. Agric. Sci. 3(1):66-74.

Lammerts van Bueren, E.T., and J.R. Myers (eds). 2012. Organic crop breeding. Wiley-Blackwell, John Wiley \& Sons, Inc., West Sussex, UK.

Lammerts van Bueren, E.T., A.M. Osman, M. Tiemens-Hulscher, P.C. Struik, S.L.G.E. Burgers, and R.C.F.M. van den Broek. 2012. Are specific testing protocols required for organic onion varieties? Analysis of onion variety testing under conventional and organic growing conditions. Euphytica 184(2):181-193. doi:10.1007/s10681-011-0545-4

Lammerts van Bueren, E.T., P.C. Struik, and E. Jacobsen. 2002. Ecological concepts in organic farming and their consequences for an organic crop ideotype. Neth. J. Agric. Sci. 50:1-26.

Link, W., and L. Ghaouti. 2012. Faba bean: Breeding for organic farming systems. In: E.T. Lammerts van Bueren and J.R. Myers, editors, Organic crop breeding. Wiley-Blackwell. John Wiley \& Sons, West Sussex, UK. p. 215-225.

Lorenzana, R.E., and R. Bernardo. 2008. Genetic correlation between corn performance in organic and conventional production systems. Crop Sci. 48(3):903-910. doi:10.2135/cropsci2007.08.0465

Löschenberger, F., A. Fleck, H. Grausgruber, H. Hetzendorfer, G. Hof, J. Lafferty, M. Marn, A. Neumayer, G. Pfaffinger, and J. Birschitzky. 2008. Breeding for organic agriculture: The example of winter wheat in Austria. Euphytica 163:469-480. doi:10.1007/s10681-008-9709-2

Mäder, P., A. Fliessbach, D. Dubois, L. Gunst, P. Fried, and U. Niggli. 2002. Soil fertility and biodiversity in organic farming. Science 296:1694-1697. doi:10.1126/science.1071148

Maynard, D.N., and G.J. Hochmuth. 2007. Knott's Handbook for vegetable growers. John Wiley \& Sons, Hoboken, NJ.

Messmer, M., I. Hildermann, K. Thorup-Kristensen, and Z. Rengel. 2012. Nutrient management in organic farming and consequences for direct and indirect selection strategies. In: E.T. Lammerts van Bueren and J.R. Myers, editors, Organic crop breeding. John Wiley \& Sons, West Sussex, UK. p. 15-38. 
Murphy, K.M., K.G. Campbell, S.R. Lyon, and S.S. Jones. 2007. Evidence of varietal adaptation to organic farming systems. Field Crops Res. 102:172-177. doi:10.1016/j.fcr.2007.03.011

Myers, J.R., L. McKenzie, and R.E. Voorrips. 2012. Brassicas: Breeding cole crops for organic agriculture. In: E.T. Lammerts van Bueren and J.R. Myers, editors, Organic crop breeding. Wiley-Blackwell. John Wiley \& Sons, West Sussex, UK. p. 251-262.

Osman, A.M., C.J.M. Almekinders, P.C. Struik, and E.T. Lammerts van Bueren. 2008. Can conventional breeding programmes provide onion varieties that are suitable for organic farming in the Netherlands? Euphytica 163:511-522. doi:10.1007/s10681-008-9700-y

Østergård, H., K. Kristensen, and J.W. Jensen. 2005. Stability of variety mixtures of spring barley. In: E.T. Lammerts van Bueren et al., editors, Proceedings of the COST SUSVAR/ ECO-PB. Workshop on Organic Plant Breeding Strategies and the Use of Molecular Markers. Louis Bolk Inst., Driebergen, the Netherlands. p. 28-30.

Pasakdee, S., G. Banuelos, C. Shennan, and W. Cheng. 2006. Organic $\mathrm{N}$ fertilizers and irrigation influence organic broccoli production in two regions of California. J. Veg. Sci. 12(4):27-46. doi:10.1300/J484v12n04_04

Przystalski, M., A.M. Osman, E.M. Thiemt, B. Rolland, L. Ericson, H. Østergård, L. Levy, M.S. Wolfe, A. Burshse, H.-P. Piepho, and P. Krajewski. 2008. Comparing the performance of cereal varieties in organic and non-organic cropping systems in different European courntires. Euphytica 163:417433. doi:10.1007/s10681-008-9715-4

Pswarayi, A., F.A. van Eeuwik, S. Ceccarelli, S. Grando, J. Comadran, J.R. Russell, N. Pecchioni, A. Tondelli, T. Akar, A. Al-Yassin, A. Benbelkacem, H. Ouabbon, W.T.B. Thomas, and I. Romagosa. 2008. Changes in allele frequencies in landraces, old and modern barley cultivars of marker loci close to QTL for grain yield under high and low input conditions. Euphytica 163:435-447. doi:10.1007/s10681-008-9726-1

Reid, T.A., R. Yang, D.F. Salmon, A. Navabi, and D. Spaner. 2011. Realized gains from selection for spring wheat grain yield are different in conventional and organically managed systems. Euphytica 177:253-266. doi:10.1007/s10681-010-0257-1
Reid, T.A., R.-C. Yang, D.F. Salmon, and D. Spaner. 2009. Should spring wheat breeding for organically managed systems be conducted on organically managed land? Euphytica 169:239-252. doi:10.1007/s10681-009-9949-9

Seufert, V., N. Ramankutty, and J.A. Foley. 2012. Comparing the yields of organic and conventional agriculture. Nature 485:229-234. doi:10.1038/nature11069

USDA-ERS. 2008. Certifier US organic acreage, by crop. Available at: www.ers.usda.gov/data-products/organic-production.aspx (accessed 20 April 2013). Economic Research Service, Washington, DC.

USDA-NASS. 2012. 2011 certified organic production survey. Available at: http://sustainableagriculture.net/wp-content/ uploads/2012/10/USDA-2011-Organic-Production-Survey. pdf (accessed 20 April 2013). National Agriculture Statistics Service, Washington, DC.

Verkerk, R., M. Schreiner, A. Krumbein, E. Ciska, B. Holst, I. Rowland, R.D. Schrijver, M. Hansen, C. Gerhauswer, R. Mithen, and M. Dekker. 2009. Glucosinolates in Brassica vegetables: The influence of the food supply chain on intake, bioavailability and human health. Mol. Nutr. Food Res. 53:219-265. doi:10.1002/mnfr.200800065

Vlachostergios, D.N., and D.G. Roupakias. 2008. Response to conventional and organic environment of thirty-six lentil (Lens culinaris Medik.) varieties. Euphytica 163:449-457. doi:10.1007/s10681-008-9712-7

VSN. 2012. GenStat for Windows. 15th ed. Available at www. vsni.co.uk/software/genstat/ (accessed 20 April 2013). VSN Int., Hemel Hempstead, UK.

Willer, H., and L. Kilcher, editors. 2012. The world of organic agriculture-Statistics and emerging trends 2011. IFOAM, Bonn, and FiBL, Frick, Germany.

Wolfe, M.S., J.P. Baresel, D. Desclaux, I. Goldringer, S. Hoad, G. Kovacs, F. Löschenberger, T. Miedaner, H. Østergård, and E.T. Lammerts van Bueren. 2008. Developments in breeding cereals for organic agriculture. Euphytica 163:323-346. doi:10.1007/s10681-008-9690-9 